\title{
Carcinogenesis Induced by UV and Ionizing Radiation
}

\author{
D. Averbeck
}

\author{
Institut Curie, Section de Recherche, UMR 218 CNRS, LCR $n^{\circ} 1$ CEA, 26 rue d'Ulm, \\ 75231 Paris cedex 05, France
}

\section{Introduction}

The increase in the incidence of cancers in the general population, in particular the rapid increase of certain types of skin cancers in recent years, represents an alarming threat for human health and a permanent challenge for scientists. In fact, a doubling of the frequence of melanoma during the last fifteen years and a doubling of non melanoma skin cancers have been observed in the last ten years in France; already in the Ile of France one counts approximately 8000 new cases per year (Doré et al. 1990, Cesarini, personal communication). The worldwide reported rapid rise in the incidence of these cutaneous malignancies (Glass and Hoover 1989) is almost entirely attributed to increased cutaneous exposure to solar UV radiation mostly related to present social behaviours including skin tanning and increased outdoor leisure activities (Mukhtar and Elmets 1996). Increased UV exposure due to stratospheric ozone depletion has also become a factor of concern (Henriksen et al. 1990) as well as indoor sunbed exposures (Autier et al. 1994. 1995). A 10\% depletion in the total-column of ozone is expected to cause, if sustained over several decades, a $20 \%$ increase in basa cell carcinoma and an about $40 \%$ increase in squamous cell carcinoma (Van der Leun, 1995). However, at the present time the decrease in ozone layers observed cannot be taken as the main factor for the increase in skin cancer.

The recent development of molecular biology has helped to get a better understanding of the mechanisms involved and to enlarge the classical concept of carcinogenesis including as principal steps the initiation and promotion of somatic cells. Actually, carcinogenesis is a multistep phenomenon (Figure 1). In particular, one of the presently favoured hypotheses describes cancer induction as a consequence of the induction of somatic mutations following the induction of DNA damage. error prone or incomplete enzymatic repair of the lesions induced leading to altered gene expression, i.e. the inactivation of certain tumour suppressor genes and/or the activation of oncogenes which favour the progression of transformed cells and tumor development. Indeed, it is thought that the activation of genes which control cell proliferation facilitates the expansion and clonal selection of initiated and genetically instable cells showing an acceleration in cell cycle progression. If such cells escape the immunologic survey system, tumor cells may built foci and, depending on their nature (see models for the induction of melanoma (Albino and Fountain 1996) and squamous cell carcinoma (Ziegler et al. 1996)), may start spreading over the whole body in form of metastasis.

That the individual repair capacities play an important role in carcinogenesis has become evident from studies on human cancer-prone diseases such as Xeroderma pigmentosum (XP) (Sarasin 1994, Kraemer 1996, Grossman and Wei 1995), Fanconi's Anemia (FA) (Moustacchi 1994) and Ataxia telangectasia (AT) (Aurias 1994). For example, XP patients are more than 1000 fold more susceptible to the induction of skin cancers by sunlight than normal individuals (Kraemer 1996).

Ultraviolet radiation can be distinguished from low density ionizing radiation such as X-rays by differences in efficacy and specificity of the cancer induced. It appears that at comparable cytotoxic level ultraviolet radiation exerts a higher mutagenic and carcinogenic potential than ionizing radiation. This is probably due to differences in energy deposition in cellular targets and in the frequency and type of lesions induced by these agents.

In physics and many industrial and medical applications, lasers are employed emitting strong monochromatic light in different regions of the electromagnetic spectrum including ultraviolet, visible and infrared radiation as well as soft $\mathrm{X}$-rays and very short wave ultraviolet radiation < $200 \mathrm{~nm}$. Despite the fact that these high- energy monochromatic light sources are highly 
focussed, the users of such light sources may well expose themselves to these types of radiation due to light scattering effects and reflection in the environment. With regard to the possible long term risks involved, the present review wants to highlight some basic facts and recent developments that contribute to our understanding of carcinogenesis induced by UV and low density ionizing radiation such as $\mathrm{X}$-rays.

\section{Induction of lesions in DNA}

In view of the induction of genotoxic, i.e. mutagenic and carcinogenic effects, it seems worth to compare the capacities of the different types of radiation to induce biologically relevant lesions in DNA. In fact, the interaction with DNA highly depends on the energy and wavelength of the emitted photons.

The biological effectiveness of ultraviolet radiation varies with the emitted wavelength which may or may not correspond to the spectral absorption of important biological intracellular (and sometimes extracellular) chromophores. In photomedicine three main wavelength regions have been distinguished (Bensasson et al. 1993) showing different photochemical reactivity towards nucleic acids (Cadet et al. 1992) : UVC (200-290 nm) which is strongly absorbed by nucleic acids (DNA and RNA) and gives rise to well-defined photolesions such as the pyrimidine dimers, the pyrimidine(6-4)pyrimidone photoproduct, the Dewar isomers and DNA cross-links; UVB $(290-320 \mathrm{~nm})$ is only slightly absorbed by nucleic acids and thus is much less effective in the induction of pyrimidine dimers and pyrimidine (6-4) pyrimidone photoproducts, how ever, it gives rise to some DNA-protein cross-links; UVA $(320-400 \mathrm{~nm})$ which constitutes together with UVB an environmentally important part of the solar spectrum is only very faintly absorbed by nucleic acids. Thus, very few dimers, 6-4 products and Dewar isomers are produced. However, many other intracellular chromophores such as tryptophane, urocanic acid, cytochrome $\mathrm{C}$, porphyrins are strong absorbers and can take part in electron and energy transfer reactions. In the presence of oxygen, type I (electron transfer) and type II (energy transfer) reactions with molecular oxygen may occur giving rise to singlet oxygen and oxygen radicals. These highly reactive oxygen species induce oxidative damage in nucleic acids and at the same time in membranes, proteins and lipids.

Although UVB constitutes only about $0.4 \%$ of the solar radiation reaching the surface of the earth its carcinogenic effects are very important (De Gruijl and Van der Leun 1994). UVA constitutes about $5.5 \%$ of the solar spectrum reaching the earth. It is also considered carcinogenic, however, its effect is more likely to be due to the indirect induction of DNA damage, to damage to membranes and receptor molecules linked to intracellular signalling pathways leading to the activation of oncogenes (ras) (Ananthaswamy and Kanjilal 1996) and to the release of cytokines, clastogenic and immunosuppressive substances (Granstein 1996). Although the distinction of different wavelength regions has been of some practical importance in the past, it should be stated here that also UVC and UVB have been found to interfere with signal transduction pathways (Pentland 1996), cytokine release and immunosuppression (Granstein 1996, Norval 1996, Krutmann et al. 1996, Takashima and Bergstresser 1996). With respect to the induction of oxidative damage, a certain similarity exists between low density ionizing and UVA radiation, for example, both agents induce DNA strand breakage, thymine glycols and 8-hydroxyguanine, and their effects depend on the antioxidant status of the cells (Tyrrell 1996)

With regard to the oxidative damage induced, it is interesting that also during normal cell metabolism oxidative damage is induced which accumulates with age. In the rat one has found that the level of oxidative damage to the base guanine (8-hydroxyguanine) is increased hundredfold in the DNA of mitochondria (involved in energy metabolism) over that in nuclear DNA, and the damage increases with age (Friedberg et al. 1995). Following UVA radiation one observes an increase in membrane damage due to lipid oxidation which is known to be an important factor of premature skin ageing. Generally a certain correlation appears to exist in animal and human beings between premature ageing and cancer development. $X$-rays and gamma-rays are known to induce over a hundred of different types of lesions in DNA including single and double-strand breaks, complex lesions such as locally multiple site damage (LMSD), modifications of bases and the sugar moieties, intra-and inter-strand cross-links as well as different kinds of protein and membrane damage (Ward 1988, 1994). On the cellular level, in 
the presence of water, most lesions arise from indirect action through the attack by radicals from water radiolysis (Bensasson et al.1993). In the presence of oxygen these radicals include oxygen derived species such as $\mathrm{O}_{2}^{-}$, singlet oxygen, $\mathrm{OH}^{\circ}$ and peroxyde radicals which are potent inducers of oxidative damage.

Because of the great variety of lesions induced, it is difficult to recognize the biologically most relevant damage. At present, it is thought that lesions such as DNA double-strand breaks and LMSD are the most harmful lesions associated with cell death, genetic instability and cancer development (Ward 1994).

It has to be noticed that, whatever the type and origin, damage induced in DNA interferes with normal DNA replication and may thus either completely inhibit DNA, RNA and protein synthesis and block cell proliferation or may constitute an initiation event in the process of carcinogenesis.

\section{The role of enzymatic repair}

Knowing that one hour sunbathing in Europe may yield up to 80000 pyrimidine dimers in DNA per cell in human skin and normal cell metabolism may produce 10000 base damages per cell and per day (Mullaart et al. 1991), it is clear that in order to survive, cells had to invent mechanisms to repair these lesions. Indeed, in the last fourty years many genetically controlled enzymatic repair systems have been discovered in living systems. Most of them have been conserved during evolution from bacteria to man (see for review, Friedberg et al. 1995).

Among the systems are error-free systems that reverse or excise the DNA lesion, others are error prone, i.e. assure cell survival but give rise to mutations. Some systems are lesion specific. Among these are the DNA ligase repairing very efficiently certain types of single strand breaks (Lindahl and Barnes 1992), the photolyases which use absorbed light energy to monomerize pyrimidine dimers (Kim and Sancar 1993), glycosylases as the formamidopyrimidine glycosylase which removes specifically a certain type of oxidative damage (Boiteux et al.1987, Laval 1996). Other systems are multi-enzymatic and more complexe. To these belongs the nucleotide excision repair system (see for review, Friedberg et al. 1995, Ma et al. 1995) which operates on bulky lesions such as pyrimidine dimers, DNA adducts, intra-and inter-strand cross-links in DNA and large base alterations which produce distortions in DNA. Others concern the excision of modified bases (Wallace 1994, Seeberg et al. 1995), the repair of mispaired bases (see for review, Kolodner 1995) and the recombinational or post-replicative repair of important DNA lesions involving strand exchanges (Friedberg et al. 1995)

The nucleotide excision repair system is very important since it can repair a variety of DNA lesions including UVC or UVB induced pyrimidine dimers as well as benzopyrendiolepoxyde DNA adducts derived from tobacco smoke and other chemical adducts. In recent years, this mechanism has been well elucidated (Friedberg et al. 1995, Ma et al. 1995). It involves approximately 50 different gene products (proteins); in addition to the proteins involved in damage recognition, incision and excision of the damage, gap filling by polymerization and final ligation, one finds associated proteins like ATPases, helicases and transcription factors. All these proteins are working together in a complex called repairosome. In recent years, it has been shown that the repair machinery is linked to transcription factors in order to repair more rapidly essential and actively transcribed genes than inactive genes (Hanawalt 1991). Most genes involved in this repair pathway were cloned, i.e. their DNA sequence identified and the corresponding proteins characterised. Using these proteins the repair system has been reconstituted in vitro (Wood and Coverly 1991). The genes and gene products were strongly conserved during evolution and many genes have direct homologs in man and baker's yeast.

Most importantly, it could be shown that defects in the repair of DNA damage are linked to a predisposition for a development of cancer (see for review, Sarasin 1994, Friedberg et al. 1995). In fact, repair deficient mutants of man exist, for example Xeroderma pigmentosum (XP) with 7 genetic complementation groups, Fanconi's anemia (FA) and Ataxia telangiectasia (AT) (Savitsky et al. 1995) conferring, respectively, a strong bypersensitivity to sun light, to cross-linking agents and to ionizing radiation and in all cases a strong predisposition to either 
the development of skin cancers (XP) (Sarasin 1994) or to different types of leukemia (FA, AT) (Cox 1994). The corresponding genes were cloned and their involvement in these diseases proven. Transgenic mice were constructed corresponding to some of these repair diseases, for instance, an XP A mouse exists which is very sensitive to solar irradiation and to the induction of skin cancer (de Vries et al. 1995). Another mouse mutant with severe combined immune deficiency (SCID) has a defect in the repair of radiation-induced double-strand breaks, recombination repair and recombination of immunoglobulines and is particularly cancer-prone (Friedberg et al. 1995).

\section{Induction of mutations}

The error-prone or incomplete repair of induced DNA damage leads to somatic mutations. In contrast to ionizing radiation, ultraviolet irradiation exhibits a specific signature at the molecular level consisting of CG---> TA transitions and tandem double events CC $->>$ TT at bipyrimidinic sites (Brash et al. 1991). The mutational spectra were obtained by DNA sequencing techniques and restriction enzyme analysis. For example, in some oncogenes of the ras type and in the cancer-suppressor gene p53 (Ananthaswamy and Kanjilal 1996), mutations GC--->AT (transitions) and also tandem mutations CC--->TT have been found corresponding to the induction of pyrimidine dimers by UVC and UVB. In skin tumors a very good correlation was observed between the sites of dipyrimidinic lesions and the mutations induced (Brash et al. 1991, Ziegler et al. 1996). In human skin cancers one observes, in 10 to $50 \%$ of the cases, mutations of the ras gene. In normal individuals one finds about $57 \%$ mutations (transversions) GC--->TA and 24\% mutations (transitions) GC--->AT (Daya-Grosjean et al. 1993). The mutational specificity was clearly established when examining mutations in the $p .53$ gene from normal and XP individuals: $67 \%$ and $90 \%$ of the tumors, respectively, showed mutations (transitions) of the GC--->AT type. In the absence of the repair of pyrimidine dimers, XP patients do not only develop more tumors but also more tumors show mutations at bipyrimidinic sites (Brash et al. 1991, Dumaz et al. 1994). The specificity of UV-induced mutations is due to the fact that the cyclobutane pyrimidine dimers and pyrimidine-pyrimidone (6-4) photoproducts are found between adjacent pyrimidines (Brash 1988).

Very recently, when analyzing the induction of mutations in another gene (APRT= adenine phosphoribosyltransferase) a molecular signature was also found for UVA consisting of mutations (transversions) AT---->CG in 37\% of the cases, whereas only 5 or $9 \%$ of such mutations were observed after UVC and UVB (Drobetsky et al. 1995, Sage et al. 1996). This finding is somewhat in agreement with the induction of oxidative damage by UVA. Moreover, it appeared that there is an increase in transversions $T--->G$ if one changes from UVC to UVB radiation (Sage et al. 1996).

Ziegler et al. 1996 have described in some detail how skin cancers may arise from excessive sun exposure and successive sumburns. In this model, UVB irrradiation induces pyrimidine dimers and 6-4 photoproducts some of which are repaired, however, some acquire a C-->>T point mutation in the $p 53$ gene. If this happens in epidermal keratinocytes, these cells become partially defective for the production of so-called sunburn cells (Ziegler et al. 1994). During the next sunlight exposure, the p53 protein becomes activated and normal UV damaged cells are lead into the pathway of programmed death (apoptosis), but, among the keratinocytes in the skin carrying a mutation of the $p 53$ gene, half die and the other half can clonally expand leading to actinic keratosis (known as a precancerous state of the skin). A second overexposure of these cells to sunlight can induce a second mutation in the $p .53$ gene on the other chromosome leading to a so-called homozygocity which can result in aneuploidy and gene amplification. Together with other UV-induced mutations in other genes this may lead to genetic instability and to squamous skin cancer (Brash et al. 1991). Following this model UVB or sun light acts twice: first in mutating the $p 53$ gene (tumor initiation step) and second, in killing normal epidermal cells (tumor promotion step) (Ziegler et al. 1996).

In contrast to UV radiation, ionizing radiation induces a high frequency of deletion type mutations rather than point mutations and specific base changes (Hutchinson 1993). Unfortunately, this cannot be regarded as a specific signature. However, after ionizing radiation specific types of chromosome aberrations are induced which are usually taken as being rather typical for ionizing radiation and are the base of biological dosimetry (Doloy 1991). 


\section{The induction of immunological changes}

In the last 20 years, a number of experimental and clinical studies have shown that ultraviolet radiation has immuno-suppressive capacities (Kripke 1990, Schwarz 1995, Krutmann et al. 1996). The first evidence came from experiments with mice showing that ultraviolet radiation by itself does not cause skin cancer but suppressed the immunosurveillance function of the skin immune system against UV induced skin cancers. That this is likely to apply also for humans can be derived from the observations that patients undergoing long-term immunosuppressive therapy show an increased risk of developing melanoma and non melanoma skin cancers (Hartevelt et al. 1990), and individuals with decreased cellular immunocompetence after UV exposure show an increased incidence of skin tumors (Yoshikawa et al. 1996, Streilein 1992). UV radiation affects the immune system by changing the morphology and function of antigen presenting cells, by inducing a systemic form of immunosuppression and stimulating, in keratinocytes in the skin, the production and release of cytokines (Schwarz 1995, Granstein 1996, Takashima and Bergstresser 1996 ). The cytokines TNF alpha (tumor necrosis factor) and the interleukin IL-10 are particularly important together with a number of other cytokines IL-1, IL-3, IL-6, IL-7, IL-8, colony stimulating factors, and specific growth factors. It is of interest that these factors can also be stimulated by bacterial and viral products, tumor promotors and other cytokines.

There is evidence that UV-induced DNA damage is involved in immunosuppression (Schwarz 1995). Incorporation of a repair enzyme (T4 endonuclease) via liposomes in mouse cells reversed UVB mediated immunosuppression (Kripke et al. 1992, Yarosh and Klein 1996). In humans, after UV exposure, the expression of the intercellular adhesion molecule ICAM- 1 , involved in the interaction between keratinocytes and leukocytes and the generation and maintainance of a variety of immune responses within human skin, was stongly modified in xeroderma pigmentosum (XP) patients lacking DNA repair capacity (Krutmann et al. 1996). Thus, UV-induced immunosuppression requires the induction of DNA damage and DNA repair enzyme activities are crucial in determining the susceptibility of a given human cell toward UVB induced immunosuppression (Krutmann et al. 1996).

From this, it appears that UV induced DNA damage and mutations act as initiating events in photocarcinogenesis but also UV radiation clearly affects the immunosurveillance and thus stimulates responses which cause tumor promotion and progression (Yarosh et al. 1992, Vink et al. 1996). This may also explain why the length of UVB exposure as well as the total fluence is a controlling factor in tumorigenesis; however, there is a somewhat unexpected influence of dose-rate on UV induced carcinogenesis (Kelfkens et al. 1991). In fact, low dose-rate exposures are more photocarcinogenic than high dose-rate exposures (Kelfkens et al. 1991). Furthermore, it has to be kept in mind that also sub-erythemal doses may well contribute to photocarcinogenesis (de Gruijl 1996).

With regard to the promotion of iumor growth, the involvement of signal transduction mechanisms in photocarcinogenesis has to be taken into account as well (Pentland 1996). In fact, it has been shown that, at physiologically relevant UV doses, several transcription factors can be activated via signal transduction pathways involving specific membrane receptors, for example, the epidermal growth factor receptor (EGF), and the activation of specific protein kinases leading to the activation of important factors such as the transcriptional activating nuclear factor B (NF- $\kappa \mathrm{B}$ ) as well as transcription factors $\mathrm{c}$-jun and c-fos (the AP-1 protein). Following UV exposure, the response in mammalian cells is regulated by transcription factors such as AP-1 and NF-KB (Holbrook and Fornace, 1991). The activation of both factors by UV irradiation is mediated by a signalling pathway involving membrane associated $\mathrm{Ha}$-Ras protein and the activation of cytoplasmic protein kinases. The Ras signalling pathway is activated in several types of cancers (Bos 1989) including UV and X-ray induced cancers. An important finding has been that these signalling pathways (NF- $\mathrm{BB}$ ) can be activated by membrane damage and oxidative damage (Devary et al. 1993). Interestingly, these types of responses are conserved between yeast and mammals (Engelberg et al. 1994). 


\section{The development of cancers after UV and ionizing radiation}

Due to the relative low penetration capacity of human tissue, ultraviolet radiation concerns basically the induction of cancers in the skin. There are several lines of evidence pointing to the fact that skin cancers are initiated from incomplete or misrepaired DNA lesions. The first evidence comes from data showing the specific absorption of DNA in the UVC and UVB ranges producing specific photolesions. The second evidence comes from animal studies showing that the epidermal load of UV-induced pyrimidine dimers,detected with monoclonal antibodies after chronic exposures of hairless mice, is inversely related to the induction times of skin carcinomas (de Gruijl 1996). The response after UVA exposure is different from that obtained by UVB indicating that other types of photodamages are involved in cancer induction by UVA (de Gruijl and Forbes 1995). As already mentionned above, in humans as well as in hairless mice, specific UV-related mutations in the tumor suppressor gene $p 53$ and the oncogene ras were found in UV-induced carcinomas. Moreover, in mice, UV-induced foci of epidermal cells were found showing aberrant $p 53$ expression long before the appearance of the ultimate tumors (de Gruijl 1996). XPA knock-out mice, lacking the DNA excision repair gene of xeroderma pigmentosum $A$, exhibited increased sensitivity to $U V$-induced carcinogenesis (de Vries et al. 1995) in line with the importance of DNA repair of UV-induced lesions for the protection against skin cancer. Furthermore, UV-induced photoadducts have been shown to be associated with the activation of many genes (Holbrook and Fornace 1991) as well with local and systemic immunosuppression (Vink et al. 1996). In fact, UV-induced skin tumors are highly immunogenic and regress upon transfer to syngeneic non-UV irradiated recipient mice. Experiments testing the immune response after UV-irradiation have shown that UV exposures induce immune suppressive mechanisms that inhibit an effective normal immune response against UV induced tumors. The immune response after UV-irradiation involves the activation of T-cells, of specific genes and the release of cytokines (Granstein 1996, Krutman et al. 1996). DNA damage to keratinocytes appears to provide an important signal for these responses because application of liposomes containing specific DNA repair enzymes (T4 endonuclease) on the skin can prevent these reactions (Yarosh and Klein 1996). Furthermore, the prevention of photocarcinogenesis, especially, the induction of non melanoma skin cancers, can be achieved by chemical protection using sunscreens, retinoids and indomethacon and by lowering the dietary fat supply (Agarwala and Mukhar 1996). However, the effectiveness of these treatments against the induction of melanoma is still a matter of discussion (Elmets and Anderson 1996).

Although the induction of cancers by ionizing radiation appears to follow the same general scheme (Figure 1), the underlying mechanisms appear to be even more complex (Cox 1994). This relies on the large variety of different lesions induced in DNA resulting in necrotic cell death, in programmed cell death (apoptosis), gene mutations leading to genetic instability and neoplastic cell transformation. On the other hand, in contrast to UV irradiation, low LET ionizing irradiation is currently used for eradication of malignant cells and tissues in the radiotherapy of tumors. It is important to recognize that, up to now, one has never been able to observe in human adults radiation induced cancers using doses below $200 \mathrm{mSv}$ (tissue equivalent dose of $200 \mathrm{~Gy}$ ) (Tubiana 1996, Köhnlein and Nussbaum 1991). A large variety of different types of cancers can be induced by ionizing radiation such as X-rays. The efficiency for cancer induction due to the differences in radiosensitivity of the tissues is especially elevated in the hematopoietic cell compartment leading to the induction of leukemia and of cancers of the lymphatic system. Since exposures to large radiation doses are usually accidental (see, for instance, Tchernobyl) and are never encountered by the general population under normal circumstances, the interest in radioprotection is focussed on low dose and low dose-rate effects.

The eareinogenic effects of ionizing radiation have been recognized from very early on, and the Intermational Commission for Radiation Protection recommended strict regulations regarding its use and tolerable exposure levels. Regularly, the recommended values are revised in order to assure the greatest possible protection of workers and the general population. Unfortunately. comparable elaborate regulations to the use of non-ionizing radiation including UV and the use of chemicals at the working place and in the environment do not yet exist. In spite of the 
relatively high background of metabolically or environmentally induced cancers, tremendous efforts are made to evaluate the carcinogenic risks of low doses and low dose-rates of ionizing radiation (Tubiana 1996, Köhnlein and Nussbaum 1991, Report of the Académie des Sciences, France 1996).

Scientifically, the underlying mechanisms are very intriguing. Certain adaptive responses following low doses of radiation have been described resulting, for example, in lower mutation frequencies after challenge to high irradiation doses (Rigaud et al. 1993), and even the occurrence of beneficial effects of low dose exposures (hormesis) has been claimed. Moreover, in contrast to the reported increase in carcinogenesis at low dose-rates of UV radiation (Kelfkens et al. 1991), low dose-rate ionizing radiation at low LET appears to result in diminished carcinogenic risks (Hall 1991).

However, in spite of this, still much caution is needed with regard to chronic low dose exposures. The interplay of different types of lesions, the involvement of error-free and errorprone repair processes, the induction of oncogenes and tumor suppressor genes at early and late times after irradiation and the apoptotic and immunological responses of cells and tissues which are likely to be involved in radiocarcinogenesis, are still largely unknown and the mechanisms need to be further elucidated. In addition, there is clinical and experimental evidence for the existence of important individual variations in the susceptibility for the induction of chromosomal damage and cancers which are based, at least in part, on genetically defined differences in the DNA repair capacities. The recently developed method of single cell electrophoresis, the so-called comet assay, provides a useful new tool for detecting these individual variations in DNA repair responses (Alapetite et al. 1996). This may offer new possibilities to understand abnormal individual responses to environmental UV exposures as well as to medical exposures to ionizing radiation in the course of radiotherapeutic treatments.

In conclusion, recent studies reveal that UV and X-ray induced carcinogenesis is evolving in a step-wise manner. Obviously, the initial exposure level is the most important requisite allowing the subsequent steps to occur (Figure 1). Chronic exposures from sun light or from diffused stray light (from lasers) of UV radiation as well as high intensity short UV exposures have to be avoided as much as possible to prevent not only ageing of the skin and of the eye lenses (cataract) but also the induction of skin cancers. Additional protection can be provided by the use of specific sunscreens absorbing in suitable wavelength ranges. The accumulation of doses leading to immunosuppression and thus to diminished defences against tumor development has to be taken into account as well. Both, UV and $X$-ray induced carcinogenesis appear to involve changes in gene regulation and immunosuppressive responses that are difficult to overcome. Moreover, as after exposures to chemical and environmental carcinogens (tobacco smoke etc.), the individual susceptibility to cancer induction has to be taken into account.

\section{References}

Agarwal, R. and H. Mukhtar (1996) Chemoprevention of photocarcinogenesis. Photochem. Photobiol. 63, 440-444.

Alapetite, C., T. Wachter, E. Sage and E. Moustacchi (1996) Use of the alkaline comet assay to detect DNA repair deficiencies in human fibroblasts exposed to UVC, UVB, UVA and $\gamma$-rays. Int. J. Radiat. Biol. 69, 359-369.

Albino, A.P. and J. W. Fountain (1996) Oncogenes and tumor suppressor genes in cutaneous malignant melanoma. Photochem. Photobiol. 63, 412-418.

Ananthaswamy, H.N. and S. Kanjilal (1996) Oncogenes and tumor suppressor genes in photocarcinogenesis. Photochem. Photobiol. 63, 428-432.

Aurias, A. (1994) Ataxie-télangiectasie: aspects cliniques, épidémiologiques et gémétiques. Médecine/sciences, 10, 957-961. 
Autier, P., J.F. Doré, F. Lejeune, K.F. Koelmel, O. Gefeller, P. Hille, J.P. Cesarini, D. Liénard, A. Liabeuf, M. Joarlette, P. Chemaly, K. Hakim, A. Koeln and U.R. Kleeberg (1994) Cutaneous melanoma and exposure to sunlamps or sunbeds: an EORTC multicenter case-control study in Belgium, France and Germany. Int. J. Cancer 58, 809-813.

Autier, P., J.F. Doré, E. Schiflers, J.P. Cesarini, A. Bollaerts, K.F. Koelmel, O. Gefeller, A. Liaboeuf, F. Lejeune, D. Liénard, M. Joarlette, P. Chemaly for the EORTC Melanoma Copperative Group (1995) Melanoma and use of sunscreens: an EORTC case-control study in Germany, Belgium and France. Int. J. Cancer 61, 749-755

Bensasson, R.V., E.J. Land and T.G. Truscott (1993) Excited states and free radicals in biology and medicine, Oxford University Press, Oxford, UK, pp. 1-431

Boiteux, S., T.R. O'Connor and J. Laval (1987) Formamidopyrimidine-DNA glycosylase of Escherichia coli: :cloning and sequencing of the fpg structural gene and overproduction of the protein. EMBO J., 6, 3177-3183.

Bos, J.L. (1989) ras oncogenes in human cancer: a review. Cancer Res. 49, 4682-4689.

Brash, D.E. (1988) UV mutagenic photoproducts in $E$. coli and human cells: a molecular genetics perspective on human skin cancer. Photochem. Photobiol. 48, 59-66.

Brash, D.E., J.A. Rudolph, J.A. Simon, A. Lin, G.J. McKenna, H.P. Baden, A.J. Halperin and J. Pontén (1991) A role for sunlight in skin cancer: UV-induced p53 mutations in squamous mouse cell carcinoma. Proc. Natl. Acad. Sci. USA, 88, 10124-10128.

Cadet, J., C. Anselmino, T. Douki and L. Voituriez (1992) Photochemistry of nucleic acids in cells. J. Photochem. Photobiol. 15, 277-298.

Cox, R. (1994) Molecular mechanisms of radiation oncogenesis. Int. J. Radiat. Biol. 65, 5764.

Daya-Grosjean,L., C. Robert, C. Drougard, H. Suarez and A. Sarasin (1993) High mutation frequency in ras genes of skin tumors isolated from DNA repair deficient Xeroderma pigmentosum patients. Cancer Res. 53, 1625-1629.

de Gruijl, F. R. (1996) Photobiology of photocarcinogenesis. Photochem. Photobiol.63, 372375.

de Gruijl, F.R. and P.D. Forbes (1995) UV-induced skin cancer in a hairless mice model. Bio Essays 17, 651-660.

de Gruijl, F.R. and J. C. Van der Leun (1994) Estimate of the wavelength dependency of ultraviolet carcinogenesis in humans and its relevance to the risk assessment of a stratospheric ozone depletion. Health Phys. 67, 314-325.

de Vries, A., C. Th. M. van Oostrom, F.M.A.Hofhius, P.M. Dortant, R.J. W. Berg, F.R. de Gruijl, P.W. Wester, C.V. van Kreijl, P.J. A. Capel, H. van Steeg and S. J. Verbeek (1995) Increased susceptibility to ultraviolet-B and carcinogens of mice lacking the DNA excision repair gene XPA. Nature 377, 169-173.

Devary, Y., C. Rosette, J.A. DiDonato and M. Karin (1993) NF-кB activation by ultraviolet light not dependent on a nuclear signal. Science 261, 1442-1445.

Doloy, M.-T. (1991) Dosimétrie basée sur le denombrement des anomalies chromosomiques contenues dans les lymphocytes sanguins. Radioprotection, 26, suppl. 1, 171-184. 
Doré, J.F., C. S. Muir and F. Clerc (1990) Soleil et mélanome. Analyse des risques de cancers cutanés moyens de prevention, INSERM, La Documentation Française, Paris, pp. 1- 186.

Drobetsky, E., J. Turcotte and A. Chateauneuf (1995) A role for ultraviolet A in solar mutagenesis. Proc. Natl. Acad. Sci. USA 92, 2350-2354.

Dumaz, N. , A. Stary, T. Sioussi, L. Daya-Grosjean and A. Sarasin (1994) Can we predict solar ultraviolet radiation as the causal event in human tumours by analysing the mutation spectra of the p53 gene. J. Photochem. Photobiol. 307, 375-386.

Elmets, C.A. and C. Y. Anderson (1996) Sunscreens and photocarcinogenesis: an objective assessment. Photochem. Photobiol. 63, 435-440.

Engelberg, D., C. Klein, H. Martinetto, K. Struhl, and M. Karin (1994) The UV response involving the Ras signalling pathway and AP-1 transcription factors is conserved between yeast and mammals. Cell 77, 381-390..

Friedberg, E.C., G.C. Walker and W. Siede (1995) DNA Repair and mutagenesis, ASM Press, Washington, D.C., USA, pp. 1-690.

Glass, A. G. and R.N. Hoover (1989) The emerging epidemic of melanoma and squamous cell skin cancer. JAMA 262, 2097-2102.

Granstein, R.D. (1996) Cytokines and photocarcinogenesis. Photochem. Photobiol. 63, 390394.

Grossman, L and Q. Wei (1995) DNA repair and epidemiology of basal cell carcinoma. Clin. Chem. 41, 1854-1863.

Hall, E.J. (1991) Weiss lecture: The dose-rate factor in radiation biology. Int. J. Radiat. Biol. $59,595-610$.

Hanawalt,P.C. (1991)Heterogeneity of DNA repair at the gene level. Mutat. Res. 247, 203211.

Hartevelt, M. M., J.N. Bouver-Bacinck, A.M. Kootte, B.J. Vermeer and J.P. Vandenbroucke (1990) Incidence of skin cancer after fetal transplantation in the Netherlands. Transplantation 49, 506-509.

Henriksen, T., A. Dahlbeck, S. Larsen and J. Moan (1990) Ultraviolet radiation and skin cancer. Effect of an ozone layer depletion. Photochem. Photobiol. 51, 579-584.

Holbrook, N.J. and A.J. Fornace, Jr. (1991) Response to adversity: molecular control of gene activation following genotoxic stress. New Biol. 3, 825-833.

Hutchinson, F. (1993) Molecular biology of mutagenesis of mammalian cells by ionizing radiation. Sem. Cancer Biol. 4, 85-92.

Kelfkens, G., H. van Weelden, F. de Gruijl and J. van der Leun (1991) The influence of doserate on ultraviolet tumorigenesis. J. Photochem. Photobiol. 10, 41-50.

Kim, S.T. and A. Sancar (1993) Photochemistry, photophysics and mechanisms of pyrimidine dimer repair by DNA photolyase. Photochem. Photobiol. 57, 895-904

Köhnlein, W. and R.H. Nussbaum (1991) Reassessment of radiogenetic cancer risk and mutagenesis at low doses of ionizing radiation. In Advances in Mutagenesis Research Vol. 3, Ed. G. Obe, Springer Verlag, Berlin-Heidelberg, pp. 53-80. 
Kolodner, R.D. (1995) Mismatch repair: mechanisms and relationship to cancer susceptibility. Trends in Biochem. 20, 397-401.

Kraemer, K.H. (1996) Lessons learned from Xeroderma pigmentosum. Photochem. Photobiol. 63, 420-422..

Kripke, M.L. (1990) Photoimmunology, Photochem. Photobiol. 52, 919-924

Kripke, M.L., P.A. Cox, L.G. Alas, and D.B. Yarosh (1992) Pyrimidine dimers in DNA initiate systemic immunosuuppression in UV-irradiated mice. Proc. Natl. Acad. USA 89, 7516-7520.

Krutmann, J., C. Ahrens, L. Roza and C. F. Arlett (1996) The role of DNA damage and repair in ultraviolet $B$ radiation-induced immunomodulation: relevance for human photocarcinogenesis. Photochem. Photobiol. 63, 394-396.

Laval, J. (1996) Role of DNA repair enzymes in the cellular resistance to oxidative stress, Path. Biol. 44, 14-24.

Lindahl, T. and D.E. Barnes (1992) Mammalian DNA ligases. Annu. Rev. Biochem. 61, 251281 .

Ma, L., J.H.J. Hoeijmakers,and A.J. van der Eb (1995) Mammalian nucleotide excision repair. Biochim. Biophys. Acta 1242, 137-164.

Moustacchi, E. (1994) Biologie cellulaire et moléculaire de l'anémie de Fanconi. Médecine /sciences $10,979-985$.

Mukhtar, H. and C.A. Elmets (1996) Photocarcinogenesis: mechanisms, models and human health implications. Photochem. Photobiol. 63, 356-357.

Mullaart,E., P.H.M. Lohman, F. Berends and J. Vijg (1991) DNA damage metabolism and aging. Mutat. Res. 237, 189-210.

Norval, M. (1996) Chromophore for UV-induced immunosuppression: urocanic acid. Photochem. Photobiol. 63, 386-390.

Pentland, A.P. (1996) Signal transduction mechanisms in photocarcinogenesis. Photochem. Photobiol. 63, 379-380.

Rapport de L'Académie des Sciences: Problèmes liés aux effets de faibles doses des radiations ionisantes. October 1995, Rapport n³ 34 , Académie des Sciences, Paris, pp.1-121

Rigaud, O., D. Papadopoulo and E. Moustacchi (1993) Decreased deletion mutation in radioadapted human lymphoblasts. Radiat. Res. 133, 94-101.

Sage,E., B. Lamolet, E. Brulay, E. Moustacchi, E. Chateauneuf and E. Drobetsky (1996) Mutagenic specificity of solar UV light in nucleotide excision repair-deficient rodent cells. Proc. Natl. Acad. Sci. USA, 93, 176-180.

Sarasin, A.(1994) Les gènes humains de la réparation de l'ADN. Médecine/scienes 10, 43-54.

Savitsky, K., A. Bar-Shira, S. Gilad, G. Rotman, Y. Ziv, L. Vanagaite, D.A. Tagle, S. Smith, T. Uziel, S. Sfez, M. Ashkenazi, I. Pecker, M. Frydman, R. Harnik, S.R. Patanjali, A. Simmons, G.A. Clines, A. Sartiel, R.A. Gatti, L. Chessa, O. Sanal, M.F. Lavin, N.G.J. Jaspers, A.M.R. Taylor, C.F. Arlett, T. Miki, S.M. Weissman, M. Lovett, F.S. Collins and 
Y. Shiloh (1995) A single ataxia telangiectasia gene with a product similar to PI-kinase. Science $268,1749-1753$.

Schwarz,T. (1995) Solar light and immune response: a review. In: Ozone, Sun, Cancer Molecular and cellular mechanisms Prevention, Eds. L. Dubertret, R. Santus and P. Morlière, Les Editions INSERM, Paris,France, pp. 155-161.

Seeberg, E., L. Eide and M. Bjoras (1995) The base excision repair pathway. Trends in Biochem. 20, 391-397.

Streilein, J.W. (1992) Immunogenic factors in skin cancers. N. Engl. J. Med.325, 884-886.

Takashima, A. and P. Bergstresser (1996) Impact of UVB radiation on the epidermal cytokine network. Photochem. Photobiol. 63, 397-400.

Tubiana, M. (1996) Effets cancérogènes des faibles doses du rayonnement ionisant. Radioprotection 31, pp. 155-191.

Tyrrell, R. M. (1996) Oxidant, antioxidant status and photocarcinogenesis: the role of gene activation. Photochem. Photobiol. 63, 380-383.

Van der Leun, J.C. (1995) Influence of ozone depletion on the skin responses to solar ultraviolet radiation. In Ozone, Sun, Cancer, Molecular and cellular mechanisms, Eds. L. Dubertret, R. Santus, and P. Morlière, Lres Editions INSERM, Paris, pp. 104-107.

Vink, A.A., D.B. Yarosh and M. L. Kripke (1996) Chromophore for UV-induced immunosuppression: DNA. Photochem. Photobiol. 63, 383-386.

Wallace, S.S. (1994) DNA damages proceed by base excision repair: biological consequences. Int. J. Radiat. Biol., 66, 579-589

Ward, J.F. (1988) DNA damage produced by ionizing radiationin mammalian cells: identities, mechanisms of formation and reparability. Progr. Nucl. Acid Res. Mol. Biol. 35, 95-125

Ward, J.F. (1994) The complexity of DNA damage: relevance to biological consequences. Int. J. Radiat, Biol. 66, 427-432.

Wood, R.D. and D. Coverly (1991) DNA excision repair in mammalian cell extracts. BioEssays 13, 447-453.

Yarosh, D., L.G. Alas, V. Yee, A. Oberyszyn, J. T. Kibitel, D. Mitchell, R. Rosenstein, A. Spinowitz and M. Citron (1992) Pyrimidine dimer removal enhanced by DNA repair liposomes reduces the incidence of UV skin cancer in mice. Cancer Res. 52, 4227-4231.

Yarosh, D.B. and J. Klein (1996) DNA repair enzymes in prevention of photocarcinogenesis. Photochem. Photobiol. 63, 445-447.

Yoshikawa, T., V. Rae, W. Bruins-Slot, J.-W. van den Berg, J. R. Taylor and J. W. Streilein (1996) Suceptibility to effects of UVB radiation on induction of contact hypersensitivity as a risk factor of skin cancer in man. J. Invest. Dermatol. 95, 530-534.

Ziegler, A., A.S. Jonason, D.J. Leffel, J.A. Simon, H.W. Sharma, J. Kimmelmann, L. Remington, T. Jacks and D.E. Brash (1994) Sunburn and p53 in the onset of skin cancer. Nature $372,773-776$

Ziegler, A., A. Jonason, J. Simon, D. Leffel and D.E. Brash (1996) Tumor suppressor gene mutations and photocarcinogenesis. Photochem. Photobiol.63, 432-435. 


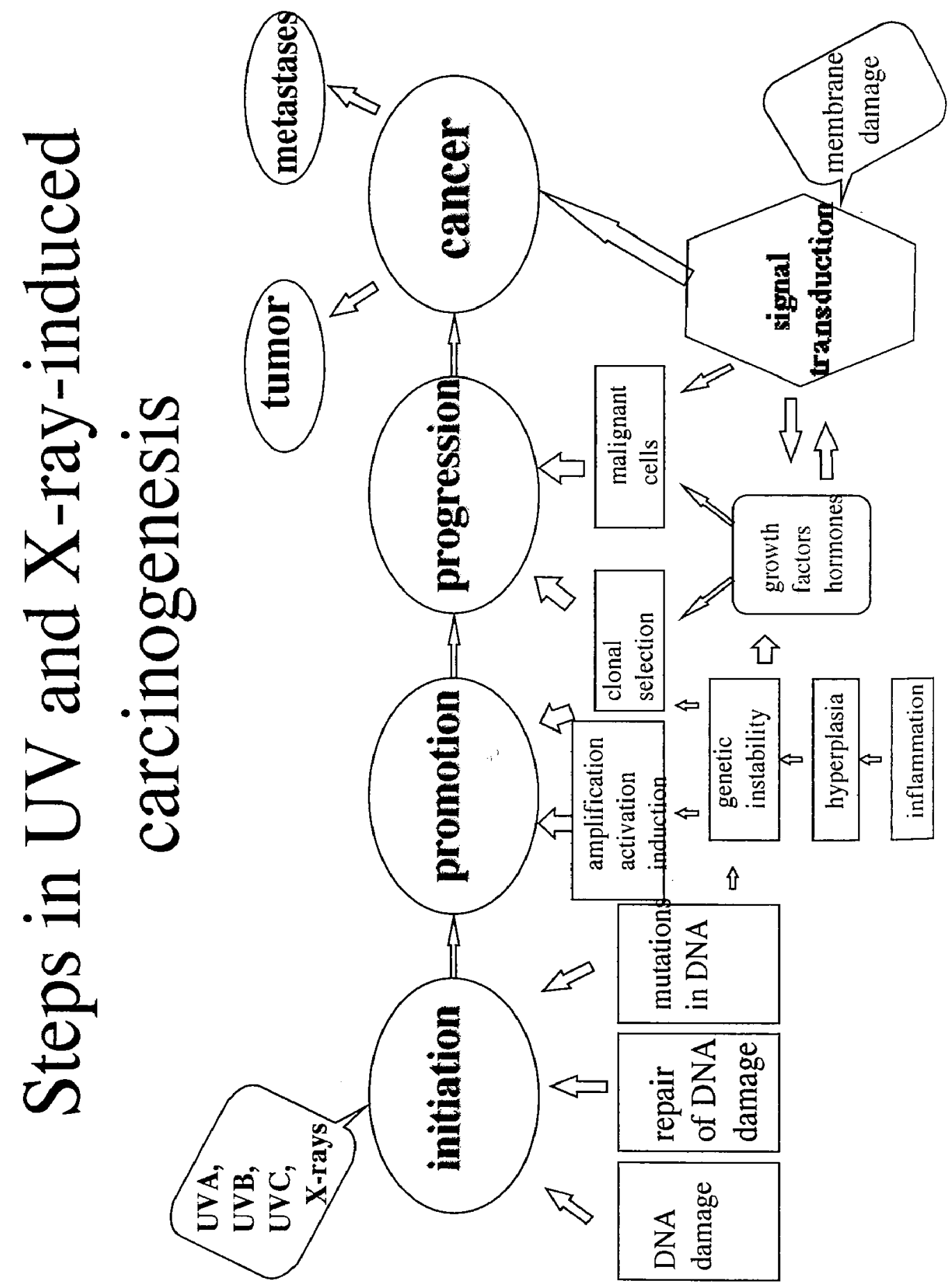

